\title{
Analysing the protective potential of padded soccer goalkeeper shorts
}

\author{
K.-U. Schmitt ${ }^{1,2}$, M. Nusser ${ }^{1}$, S. Derler ${ }^{3}$, P. Boesiger ${ }^{1}$ \\ ${ }^{1}$ Institute for Biomedical Engineering, University and ETH Zurich, Switzerland \\ ${ }^{2}$ AGU Zürich, Switzerland \\ ${ }^{3}$ Laboratory for Protection and Physiology, Swiss Federal Laboratories for Materials Testing \\ and Research (EMPA), St. Gallen, Switzerland
}

Corresponding author:

PD Dr. Kai-Uwe Schmitt

Institute for Biomedical Engineering

University and ETH Zurich

Gloriastrasse 35

8092 Zurich, Switzerland

schmitt@ethz.ch

Tel: +41446327536

Fax: +41446321193

\section{Co-Authors:}

Michaela Nusser, MSc - same address as above

Prof. Dr. Peter Boesiger - same address as above

Dr. Siegfried Derler - Laboratory for Protection and Physiology, Swiss Federal Laboratories for Materials Testing and Research (EMPA), Lerchenfeldstrasse 5, CH9014 St. Gallen, Switzerland

Keywords: soccer, hip injuries, biomechanics, injury prevention

This document is the accepted manuscript version of the following article:

Schmitt, K. U., Nusser, M., Derler, S., \& Boesiger, P. (2010). Analysing the protective potential of padded soccer goalkeeper shorts. British Journal of sports Medicine, 44(6), 426-429. https://doi .org/10.1136/bjsm.2008.048058 


\section{ABSTRACT}

Objective: The potential of currently available padded soccer goalkeeper shorts to prevent hip injuries sustained in side jumps was investigated.

Design: Within the scope of this study a survey among professional and amateur goalkeepers, trainers as well as the medical staff was performed. In addition commercially available shorts were impact-tested using an artificial hip model. The results were compared to requirements established for hip protectors for elderly.

Results: As results of the survey it was found that contusions and abrasions were observed most often for all players. Fractures and arthritis were only reported by amateur players, whereas bursitis was more frequently observed by professional players. Amateurs have a significantly higher risk of injury than professional players and the higher injury risk during training is significantly higher compared to the injury risk during a match. No difference of the injury risk was found between goalkeepers wearing padded shorts and those who did not.

Impact tests indicated a wide range of performance of the currently available products. The padded shorts generally reduce impact forces, but mostly perform poorly. Only shorts that were made of visco-elastic foam fulfilled the basic requirements requested for hip protectors for elderly.

Conclusions: The quality of most of the currently available goalkeeper shorts needs to be improved in order to effectively prevent hip injury sustained in side jumps.

\section{INTRODUCTION}

Soccer is a very popular sport that also accounts for a high number of injuries ${ }^{1,2,3}$. Depending on the study design and the definitions used, the incidence rates reported in the literature differ. According to the Swiss Council for Accident Prevention, soccer injuries account for about $50 \%$ of all injuries reported in ball sports ${ }^{1}$. Investigating soccer injuries during the 2004 Olympic Games, Junge et al. ${ }^{4}$ determined an incidence rate of 2.4 injuries per match. $70 \%$ of these injuries affected the lower extremity and most frequently contusions were observed. However, in a small number of cases also more severe injuries like fractures were reported. Similarly Goga and Gongal ${ }^{5}$ presented a study showing that amateur soccer players sustain severe injuries.

Most literature focuses on injuries of field players, only few studies like Ruppert ${ }^{6}$ or Ostojic $^{7}$ report injuries specific to goalkeepers with the latter work indicating that goalkeepers are more frequently injured than field players. This study aimed at investigating hip injuries of goalkeepers. Although there are not many publications on injury rates, causation and the underlying biomechanics, special shorts for goalkeepers that are meant to prevent hip injury are commercially available. There exist several types of shorts by different manufacturers which basically have in common that they exhibit a padded area on both sides of the upper leg (roughly over the region of the greater trochanter). The use of such protective clothing is recommended by the FIFA (Fédération Internationale de Football Association) ${ }^{8}$. In contrast to hip protectors for elderly where several efforts were undertaken to analyse the biomechanical background and assess the quality of protectors ${ }^{9,10,11,12}$, the performance of goalkeeper shorts remains unclear.

In this study the protective potential that soccer goalkeeper shorts offer in side jumps was investigated by a survey among players as well as by experimental tests using currently available off-the-shelf goalkeeper shorts.

\section{MATERIALS AND METHODS}


The approach used to analyse the effect of padded goalkeeper shorts was twofold. On the one hand a survey was conducted among players, trainers and the medical staff of soccer clubs and on the other hand several shorts were investigated experimentally. The load case that this study focussed on was a jump to the side as can frequently be observed during matches when a goalkeeper tries to reach a ball that targets the outer area of the goal.

The survey was based on questionnaires which were sent to all professional female and male goalkeepers of the highest Swiss and German soccer leagues, their trainers as well as the medical staff of their clubs. The questions were related to different hip injuries sustained by jumps to the side, the training routines of goalkeepers as well as the use of padded shorts. 79 questionnaires were sent to professional male players, 29 to professional female players, 47 to trainers and 44 to medical staff.

In addition an online questionnaire addressing amateur players was developed. All amateur goalkeepers of the (lower) German speaking Swiss soccer leagues were invited to participate. The questions were designed such that they could be compared to those addressing the professional players. The results of the survey were analysed by means of descriptive statistics. To check for differences between certain groups, chi-squared tests were performed. The statistics package of Microsoft Excel software was used for all evaluations.

In the second part of the study, the commercially available shorts were impact-tested by means of an anatomical hip model which is used to assess the quality of hip protectors for the elderly ${ }^{11}$. The experimental set-up is shown in Figure 1 . The hip was dressed with a pair of goalkeeper shorts such that the protector was placed over the greater trochanter area. A mass of $10 \mathrm{~kg}$ falling from of a height $0.5 \mathrm{~m}$ was used to apply impact loads. The external impact force acting on the striker $\left(F_{\text {impact }}\right)$ as well as the resultant forces inside the femoral neck $\left(F_{\text {neck }}\right)$ and in vertical direction $\left(F_{\text {vertical }}\right)$ were measured. Force-deformation curves were derived from these recordings since such curves are an indicator for the energy that was absorbed by the protector. Additionally the shorts were rated according to test criteria for hip protectors used in Switzerland ${ }^{13}$. A product that fulfils different requirements is granted a quality label and recommended for use by the Swiss Council for Accident Prevention. Important indicators for the quality of the mechanical properties are the so-called safety factors $^{13,14}$. These safety factors were derived from fall experiments and take into account several parameters including the geometrical and cross-sectional parameters of the femoral neck, bone strength as well as tensile and compressive stress. With respect to hip protectors for elderly, minimum safety factors of 1.7 for both the compressive and tensile stresses in the femoral neck are required to pass the test. In this study a total of 8 different commercially available shorts for goalkeepers were investigated (manufacturers: Adidas, Kappa (two different types), Puma, Nike, Lotto, Joma, Mc David). In addition one pair of padded shorts sold for snow sports and one for floor ball as well as two different hip protectors for elderly were included in the test programme.

\section{RESULTS}

40 questionnaires were returned from professional male goalkeepers (i.e. a return rate of $51 \%)$ and 14 female players responded (48\%). Additionally 23 trainers (49\%) and 9 team doctors (20\%) returned the questionnaires. Due to the low response of the medical staff, these answers were excluded from statistical analysis. The online questionnaire was filled-in by 186 male and 17 female amateur goalkeepers.

The average age of all male players was $26 \pm 8.7$ years, the female players were 22 \pm 5.7 years old. Results concerning type and frequency of hip injuries reported after lateral jumps are summarized in Table 1. As can be seen, contusions and abrasions were observed most often for all players. Fractures and arthritis were only reported 
by amateur players, whereas bursitis was more frequently observed by professional players. It also turned out that the perception of injuries between trainers and players is different. Trainers reported a higher percentage of bursitis and synovitis, but less abrasions.

Table 1: Type and frequency of hip injuries as reported in the questionnaires.

\begin{tabular}{lccccc}
\hline $\begin{array}{l}\text { Injuries reported } \\
\text { (Number of returned }\end{array}$ & $\begin{array}{c}\text { Male } \\
\text { professionals } \\
\text { questionnaires) }\end{array}$ & $\begin{array}{c}\text { Female } \\
\text { professionals } \\
\mathbf{( 4 0 / 1 0 0 \% )}\end{array}$ & $\begin{array}{c}\text { Male } \\
\text { amateurs }\end{array}$ & $\begin{array}{c}\text { Female } \\
\text { amateurs }\end{array}$ & Trainers \\
\hline Contusion & $19 / 48 \%$ & $10 / 71 \%$ & $129 / 69 \%$ & $10 / 59 \%$ & $13 / 56 \%$ \\
Abrasion & $32 / 80 \%$ & $14 / 100 \%$ & $170 / 92 \%$ & $17 / 100 \%$ & $3 / 13 \%$ \\
Fracture & $0 / 0 \%$ & $0 / 0 \%$ & $3 / 2 \%$ & $0 / 0 \%$ & $0 / 0 \%$ \\
Bursitis & $9 / 23 \%$ & $4 / 29 \%$ & $8 / 4 \%$ & $0 / 0 \%$ & $11 / 48 \%$ \\
Synovitis (hip joint) & $8 / 20 \%$ & $1 / 7 \%$ & $17 / 9 \%$ & $2 / 12 \%$ & $6 / 26 \%$ \\
Arthrosis (hip joint) & $0 / 0 \%$ & $0 / 0 \%$ & $5 / 3 \%$ & $0 / 0 \%$ & $1 / 4 \%$ \\
\hline
\end{tabular}

The results of the chi-squared statistics indicated significant differences between the injury rate of amateurs and professionals with amateurs being more often injured than professionals (Table 2). Furthermore the analysis showed that there is a significantly higher injury risk during training compared to the injury risk during a match. Gender and age did not significantly influence the prevalence of hip injuries. The statistics did not indicate a difference of the injury risk between goalkeepers wearing padded shorts and those who did not. Results concerning other aspects of the survey (like training routines, education, influence of different ground properties) are omitted here.

Table 2: Summary of the results obtained by the chi-squared statistics. A significance level of $5 \%$ (i.e. p-value 0.05 ) was chosen. The minimum of answers that were required to define a group was 6 . For various groups, it was tested whether there is a significant difference of the injury risk (regarding any injury).

\begin{tabular}{llll}
\hline groups & p-value & interpretation \\
\hline $\begin{array}{l}\text { Male vs. female goalkeepers (all } \\
\text { players) }\end{array}$ & 0.184 & $\begin{array}{l}\text { Not significant. The injury risk for hip } \\
\text { injuries is not different between male and } \\
\text { female goalkeepers. }\end{array}$ \\
$\begin{array}{l}\text { Injury rate for different age groups (all } \\
\text { players): younger than 20, } 0.098-30,\end{array}$ & $\begin{array}{l}\text { Not significant. The injury risk for hip } \\
\text { injuries is not different between male and } \\
\text { older than } 30\end{array}$ & $\begin{array}{l}\text { female goalkeepers. } \\
\begin{array}{l}\text { Professional vs. amateur goalkeepers } \\
\text { (all players) }\end{array}\end{array}$ & $\begin{array}{l}\text { Strongly significant. Amateur goalkeepers } \\
\text { face a higher injury risk than professional } \\
\text { players. }\end{array}$ \\
$\begin{array}{l}\text { Injury rate during match vs. training } \\
\text { (all players) }\end{array}$ & 0.000 & $\begin{array}{l}\text { Strongly significant. During training the } \\
\text { injury risk is higher than during a match. }\end{array}$
\end{tabular}


Injury rate of players wearing padded shorts vs. those who do not wear such shorts (all players)

Injury rate of amateur players wearing padded shorts vs. those who do not wear such shorts (all amateur players)

Injury rate of professional players wearing padded shorts vs. those who do not wear such shorts (all professional players)

Injury rate of amateur and professional male players wearing padded shorts vs. those who do not wear such shorts (all male players) Injury rate of amateur and professional female players wearing padded shorts vs. those who do not wear such shorts (all female players)
0.932 Not significant. There is no difference in the injury rate between those wearing goalkeeper shorts and those who do not.

0.687 Not significant. There is no difference in the injury rate among amateur players wearing goalkeeper shorts and those who do not.

0.178 Not significant. There is no difference in the injury rate among professional players wearing goalkeeper shorts and those who do not.

0.673 Not significant. There is no difference in the injury rate among male players wearing goalkeeper shorts and those who do not.

0.100 Not significant. There is no difference in the injury rate among female players wearing goalkeeper shorts and those who do not.

The results obtained from the experimental testing of the different shorts are presented in Table 3 and Figure 2. Determining the safety factor as a measure, it can be seen from Table 3 that there is a wide spread in performance among the shorts tested. While most designs rate poorly, some shorts get very close or even manage to partially fulfil the requirements that were developed for hip protectors for elderly.

Table 3: Experimental results showing the forces and safety factors as determined from impact testing. To pass the test criteria for hip protectors for elderly both safety factors must be 1.7 or higher. If the hip model is tested without shorts, the following forces are recorded: $F_{\text {impact }}=7005 \mathrm{~N}, F_{\text {neck }}=5330 \mathrm{~N} F_{\text {vertical }}=5850 \mathrm{~N}$.

\begin{tabular}{ccccccc}
\hline test no. & & $\mathbf{F}_{\text {impact }}$ & $\mathbf{F}_{\text {neck }}$ & $\mathbf{F}_{\text {vertical }}$ & $\begin{array}{c}\text { safety factor } \\
\text { tension }\end{array}$ & $\begin{array}{c}\text { safety factor } \\
\text { compression }\end{array}$ \\
& & {$[\mathbf{N}]$} & {$[\mathbf{N}]$} & {$[\mathbf{N}]$} & {$[-]$} & {$[-]$} \\
\hline A & for elderly & 3506 & 1961 & 2161 & 2.89 & 2.33 \\
B & for elderly & 3266 & 2007 & 2211 & 2.83 & 2.28 \\
C & floor ball & 4307 & 2423 & 2673 & 2.28 & 1.84 \\
D & soccer & 4558 & 2773 & 3060 & 2.01 & 1.61 \\
E & soccer & 5184 & 3455 & 3814 & 1.59 & 1.27 \\
F & soccer & 5456 & 3666 & 4044 & 1.51 & 1.20 \\
G & soccer & 5508 & 3747 & 4134 & 1.46 & 1.17
\end{tabular}




\begin{tabular}{ccccccc}
$\mathrm{H}$ & soccer & 5513 & 3768 & 4155 & 1.46 & 1.16 \\
$\mathrm{I}$ & soccer & 5738 & 3968 & 4382 & 1.38 & 1.10 \\
$\mathrm{~J}$ & soccer & 5771 & 3973 & 4385 & 1.37 & 1.09 \\
$\mathrm{~K}$ & snow sports & 5320 & 4009 & 4431 & 1.35 & 1.08 \\
$\mathrm{~L}$ & soccer & 5823 & 4062 & 4481 & 1.35 & 1.07 \\
\hline
\end{tabular}

\section{DISCUSSION AND CONCLUSIONS}

In this study the protective potential of goalkeeper shorts was investigated. The survey indicated that first of all abrasions and contusions are sustained by goalkeepers when performing a side jump. In contrast to amateur players, professionals also claim to suffer from bursitis sometimes. Similar as described by Junge and Dvorak ${ }^{15}$, a different perception of the injury rate between players and trainers was recorded. This represents a general limitation of this methodology.

Whereas the survey showed a significantly higher injury risk for amateurs compared to professional players and a significantly higher injury risk during training, the use of currently available padded shorts did not influence the injury rate. Hence, the results of the survey suggest that the use of such shorts has no benefit. According to the survey the protective potential of goalkeeper shorts cannot be confirmed. However, it must be noted that the survey gives just an overall picture. Although it was possible to clearly determine the most often used brand of shorts, it was - due to a limited number of responses - not possible to compare the effectiveness of different designs of shorts (e.g. different brands or styles). A further aspect that could not be considered in this study is related to a possible shift of injury severity. It could not be determined whether wearing padded shorts does shift injuries from a more severe to a less severe level.

The results from impact testing reflected the differences in the materials used as padding. Most soccer protectors (i.e. protectors E, F, G, H, I, J, L) consist of rather thin (approx. $1 \mathrm{~cm}$ thick) padding made of fully elastic foam. Hence it is not surprising that their performance in the impact tests was very similar. Short $\mathrm{K}$ was made of stiffer foam. In isolated material tests this padding exhibited a characteristic that was shell like rather than foam like. Goalkeeper short $D$ that performed best of all soccer protectors was made of a visco-elastic material. Furthermore its foam layer covered a large area and the textile was designed such that the short was very tight. Short $C$ that is sold for floor ball goalkeepers was composed of a similar design as short D, but was slightly thicker and had also a thicker and even tighter outer textile. The hip protectors for elderly that were tested for comparison performed very well. They are made of visco-elastic material and were approx. 80-100\% thicker than the padding of the other shorts. Whereas the hip protectors for elderly showed a good capacity to absorb the impact energy that was applied, most of the other protectors performed rather poorly not reaching the required safety factor of 1.7 . In fact, only short $D$ performed well enough to reach one sufficient safety factor with respect to the force of the femoral neck. All other goalkeeper shorts indicated a limited capacity to reduce the impact force. However, a generally positive influence of such shorts was observed such that the forces are actually reduced compared to an impact without shorts. But the influence appears to be too small for most of the products to limit the forces to a clearly non-injurious level. The forces recorded at the femoral neck showed a wide span. For some soccer protectors there was twice as much force transmitted as with hip protectors for elderly and also between different goalkeeper shorts a large variation was measured. This demonstrated that the currently available goalkeeper shorts are of very different quality. Of course it must be acknowledged 
that the safety factors used here to rate the shorts were developed for quantifying the protective potential of hip protectors for elderly and therefore might have a limited relevance for goalkeeper shorts. Whereas hip protectors for elderly focus on femur fractures, goalkeeper shorts are meant to address younger healthy players. Furthermore, only one sample per brand was tested, i.e. the variability of different samples of the same brand (caused e.g. due to production variability) was not assessed. But bearing in mind the spread of the results and the large difference in the forces recorded, this variability is believed to be of minor relevance.

With regard to the results of the survey, goalkeeper shorts should focus more on the prevention of contusions instead of fractures. However, it remains to be analysed whether the biomechanical thresholds to prevent contusion in a younger individual are so much different from those that apply to an older person addressing fracture. Moreover some goalkeeper shorts (along with the shorts intended for floor ball) have shown to be able to perform nearly as good as hip protectors for elderly and thus indicate that from a technological point of view such a design is possible.

One point that was not addressed by the experiments was geometry. Although most goalkeeper protectors were similar in size and position, the tests were always performed with the pads properly positioned on the hip, i.e. the best case was tested. During practice, in contrast, it might be possible that the goalkeeper does not perfectly meet the protector in a side jump. Particularly wide shorts might allow the protector to shift away and thus limit its performance. Generally a tight short that keeps the protector in its designed position seems advantageous.

In conclusion, this study presents indications that the quality of currently available goalkeeper shorts could be improved in order to prevent hip injury sustained in side jumps. Whereas the use of safety equipment is often advocated in a very general sense, it should also be ensured that this equipment is capable of providing the protection it is meant for. The development of standardised test procedures can be one possibility to enforce a minimum quality of such sports equipment. Since it turned out that amateurs are at a significantly higher risk of hip injury, future research should particularly focus on this large group of soccer players.

\section{ACKNOWLEDGEMENTS}

The support of the Mr. Raduolf Bivetti at EMPA is highly appreciated.

\section{COMPETING INTERESTS}

None.

\section{FUNDING}

Funding for this study was obtained by EMDO Foundation, Switzerland.

\section{Figure legends (Figures were provided as PowerPoint files)}

Figure 1: The experimental set-up used consisting of the hip model with a protector placed over the greater trochanter area, schematic drawing (left) and picture (right). 
Figure 2: Force-deformation curves for shorts $A, D$ and $L$ i.e. the goalkeeper short with the highest safety factor (D), the goalkeeper short with the lowest safety factor (L) and a hip protector for elderly (A) as comparison. As can be seen better deformation capacities reduce the force peak.

\section{REFERENCES}

1. Swiss Council for Accident Prevention (bfu). Accident statistics. 2006; www.bfu.ch

2. Ekstrand J, Timpka T, Hägglund M. Risk of injury in elite football played on artificial turf versus natural grass: a prospective two-cohort study. Br J Sports Med 2006; 40:975-980

3. Meyers M, Barnhill B. Incidence, causes, and severity of high school football injuries on field turf versus natural grass: a 5-year prospective study. Am J Sports Med 2004; 32: 1626-1638

4. Junge A, Langevoort G, Pipe A, Peytavin A, Wong F, Mountjoy M, Beltrami G, Terrell $\mathrm{R}$, Holzgraefe M, Charles F, Dvorak J. Injuries in team sport tournaments during the 2004 Olympic games. Am J Sport Med 2006; 34(4): 565-576

5. Goga I, Gongal P. Severe soccer injuries in amateurs. Br J Sports Med. 2003;37:498501

6. Ruppert R. Traumatische anteriore Erstluxation der Hüfte beim Sportler. Sportverletz Sportschaden 2004; 18(1):34-36

7. Ostojic S. Comparing sports injuries in soccer: influence of a positional role. Research in Sports Medicine 2003; 11:203-208

8. Fédération Internationale de Football Association. The Football Medicine Resource Kit (F-MARC). 2005; www.fifa.com

9. Robinovitch S, Hayes W, McMahon T. Energy-shunting hip padding system attenuates femoral impact force in a simulated fall. J Biomech Eng 1995;117(4): 40913

10. Kannus P, Parkkari J, Poutala J. Comparison of force attenuation properties of four different hip protectors under simulated falling conditions in the elderly: an in vitro biomechanical study. Bone 1999; 25(2): 229-35

11. Derler S, Spierings A, Schmitt K-U. Anatomical hip model for the mechanical testing of hip protectors. Med Eng Phys 2005; 27(6): 475-85

12. van Schoor N, van der Veen A, Schaap L, Smit T, Lips P. Biomechanical comparison of hard and soft hip protectors, and the influence of soft tissue. Bone 2006; 39(2):4017

13. Swiss Council for Accident Prevention (bfu). Prüfreglement zur Erlangung des bfuSicherheitszeichens für Hüftprotektoren. 2007; report R0407.

14. Spierings A, Derler S. Assessment of hip protectors and corresponding hip fracture risk using stress calculation in the femoral neck. Med Eng Phys 2006; 25:550-559

15. Junge A, Dvorak J. Influence of definition and data collection on the incidence of injuries in football. Am J Sports Med 2000; 28(5):S40-S46

\section{Statement}

"The Corresponding Author has the right to grant on behalf of all authors and does grant on behalf of all authors, an exclusive licence (or non-exclusive for government employees) on a worldwide basis to the BMJ Publishing Group Ltd and its Licensees to permit this article to be published in British Journal of Sports Medicine editions and any other BMJPGL products to exploit all 
subsidiary rights, as set out in our licence http://bjsm.bmjjournals.com/ifora/licence.pdf " 

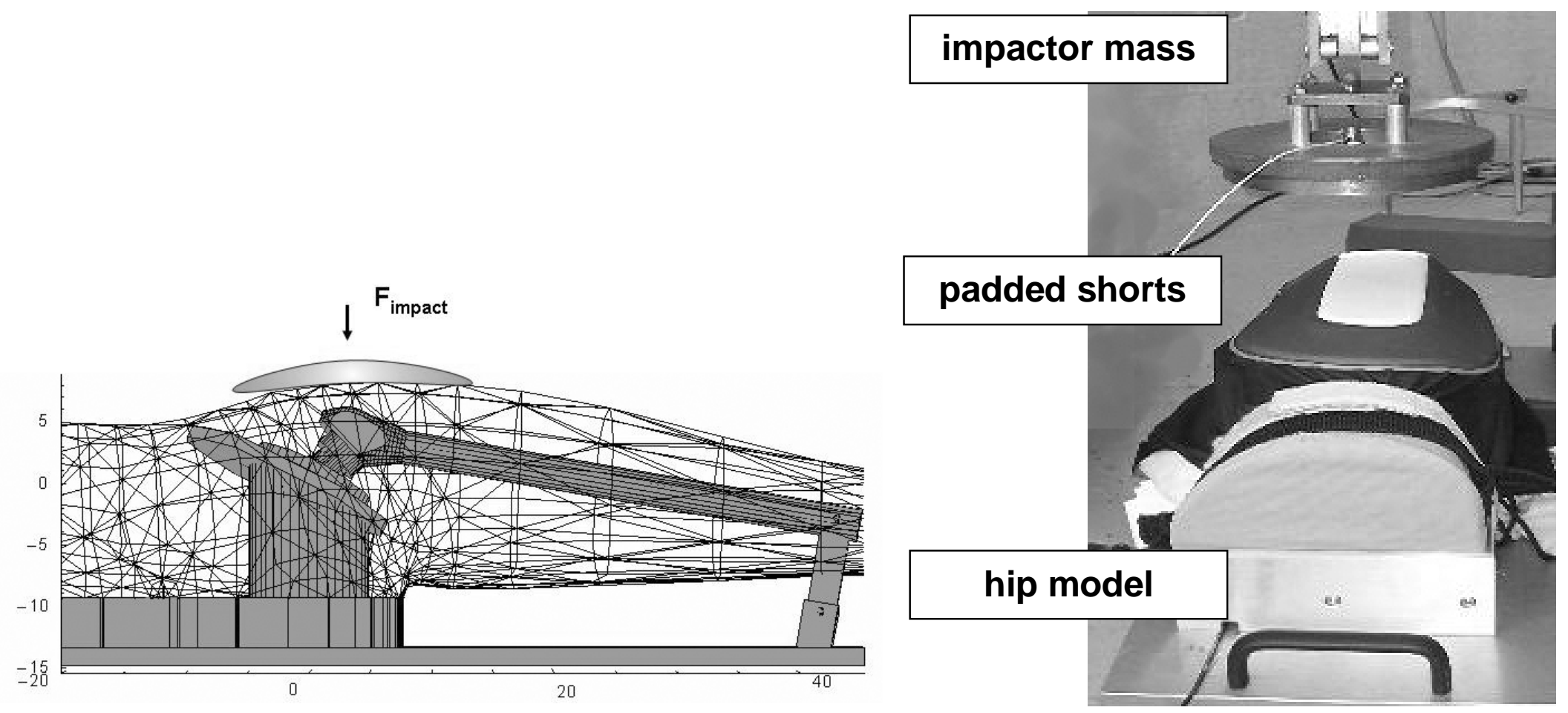

Figure 1: The experimental set-up used consisting of the hip model with a protector placed over the greater trochanter area, schematic drawing (left) and picture (right). 


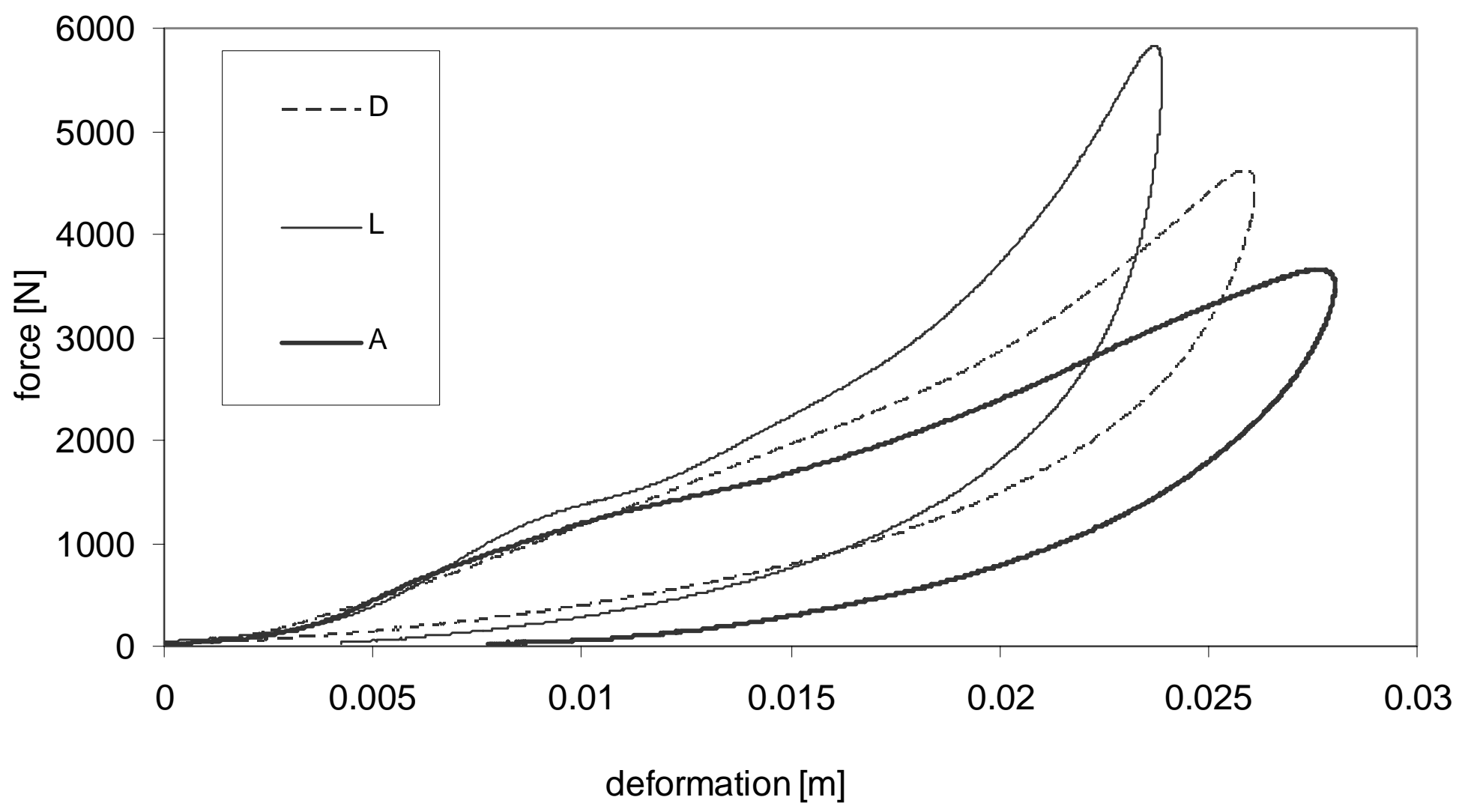

Figure 2: Force-deformation curves for shorts $A, D$ and $L$ i.e. the goalkeeper short with the highest safety factor (D), the goalkeeper short with the lowest safety factor (L) and a hip protector for elderly (A) as comparison. As can be seen better deformation capacities reduce the force peak. 